\title{
DE SABERES E DE TERRITÓRIOS: DIVERSIDADE E EMANCIPAÇÃO A PARTIR DA EXPERIÊNCIA LATINO-AMERICANA
}

\author{
Carlos Walter Porto-Gonçalves \\ Universidade Federal Fluminense
}

Nossa luta é epistêmica e política (Luis Macas - Conaie).

A importância da linguagem para o desenvolvimento da cultura está em que nela o homem estabeleceu um mundo próprio ao lado do outro, um lugar que ele considerou firme o bastante para, a partir dele, tirar dos eixos o mundo restante e se tornar seu senhor. Na medida em que por muito tempo acreditou nos conceitos e nomes de coisas como um aeternea veritates (verdades eternas), o homem adquiriu esse orgulho com que se ergueu acima do animal: pensou ter realmente na linguagem o conhecimento do mundo (Nietzsche).

\section{Desprovincianizando a razão - elementos para a crítica do eurocentrismo'}

Problematizar a relação entre saberes e territórios é, antes de tudo, por em questão a idéia eurocêntrica de conhecimento universal. Com isso não queremos

\footnotetext{
'Neste artigo dou continuidade às reflexões que venho propondo e coletivamente elaborando junto ao Grupo de Trabalho Hegemonias e Emancipações de Clacso, desde 2001. Já em 2001 iniciava Da Geografia às geo-grafias: um mundo em busca de novas territorialidades uma reflexão sobre epistemes e territórios afirmando: "Limite entre saberes, limite entre disciplinas, limite entre países. Por todo lado se fala que os limites já não são rígidos, que os entes já não são tão "claros, distintos e definidos" como recomendara René Descartes. Cada vez mais se fala de empresas internacionais, ou transnacionais ou multinacionais, assim como se fala de interdisciplinaridade, transdisciplinaridade ou multidisciplinaridade. Enfim, por todo lado são usados os prefixos inter, trans ou multi indicando que as fronteiras, sejam elas epistêmicas, sociológicas ou geográfico-políticas, se é que podemos separá-las, são mais porosas do que se acreditava" (PortoGonçalves in Ceceña e Sader, 2002: 217).
} 
recusar a idéia de que o conhecimento seja universal, mas, sim, (1) retirar o caráter unidirecional que os europeus impuseram a essa idéia (eurocentrismo) e (2) afirmar que as diferentes matrizes de racionalidade constituídas a partir de diferentes lugares, os topoi de Boaventura de Sousa Santos, são passíveis de serem universalizados, o que nos obriga a considerar os processos por meio dos quais os conhecimentos podem dialogar, se relacionar. Enfim, o que se visa é um diálogo de saberes que supere a colonialidade do saber e do poder (Quijano, 2005 [2000])

O que se critica aqui não é a idéia de pensamento universal mas, sim, a idéia de que há $U m$ e somente $U m$ pensamento universal, aquele produzido a partir de uma província específica do mundo, a Europa e, sobretudo, a partir da segunda metade do século XVIII, aquele conhecimento produzido a partir de uma sub-província específica da Europa, a Europa de fala inglesa, francesa e alemã, enfim, a segunda moderno-colonialidade, que teima em olvidar o conhecimento produzido na primeira moderno-colonialidade, aquela de fala espanhola ou portuguesa.

Com essa desprovincianização da Europa da idéia de pensamento universal o que visamos é o deslocamento do lugar de enunciação e, assim, proporcionar que outros mundos de vida ganhem o mundo, mundializando o mundo. Insistimos que não se trata de negar o pensamento europeu, o que seria repeti-lo com sinal invertido, mas sim nos propormos dialogar com ele sabendo que é europeu e, portanto, um lugar de enunciação específico, ainda que sabendo (1) que essa especificidade não é igual a outros lugares de enunciação pelo lugar que ocupa na contraditória estrutura do sistema mundo moderno-colonial, (2) nem tampouco que esse lugar de enunciação europeu seja homogêneo e não abrigue perspectivas contraditórias, seja de afirmação da ordem, seja de perspectivas emancipatórias. O liberalismo e o marxismo, ambos nascidos na Europa, não são a mesma coisa, muito embora de diferentes maneiras se vejam a braços com a colonialidade, essa dimensão não-revelada pelas duas moderno-colonialidades. Enfim, o lugar de enunciação não é uma metáfora que possa ignorar a materialidade dos lugares, enfim, a geograficidade do social e do político (PORTO-GONÇALVES, 2003).

\section{O espaço: onde habita a simultaneidade}

Para promover essa desprovincianização e o reconhecimento de novos lugares de enunciação é preciso trazer o espaço para dentro da história e deixá-lo falar. A visão unilinear do tempo silencia outras temporalidades que conformam o mundo simultaneamente. Sucessão e simultaneidade, sucessões simultâneas, eis o espaçotempo. O mundo não tem um relógio único. Nesse sentido, também o materialismo histórico deve ser geografizado - materialismo histórico-geográfico (SOJA, 1993) - o que significa abandonar uma visão linear do tempo, que certas correntes marxistas partilham com os liberais e que não é um tempo abstrato, mas o tempo 
europeu, branco, burguês e fálico da segunda moderno-colonialidade (DUSSEL, 2005 [2000]), e se abrir para as múltiplas temporalidades que conformam os lugares, as regiões, os países, enfim, os territórios que as conformam. Se o espaço é apropriado, marcado, grafado (geografado) no processo histórico tendo, assim, uma historicidade, esse fato nos impõe a necessidade de levar a sério essa geograficidade da história, inclusive, no campo das idéias, do conhecimento.

Assim, a cartografia da Terra foi grafada pelo Papa, em 1493, com um meridiano, o de Tordesilhas e, desde o século XIX, a Ciência laica se encarregaria de remarcar um novo ponto zero de onde passa a recartografar o mundo, agora a partir do meridiano de um subúrbio de Londres, Greenwich. Não olvidemos que se orientar é se dirigir para o oriente e tomar esse rumo era tomar o rumo certo na vida, tal como hoje se diz nortear. Essa troca de verbo é, também, uma troca de hegemonia geopolítica.

Embora a segunda moderno-colonialidade, aquela do Iluminismo, procure ignorar a verdadeira revolução no conhecimento da primeira moderno-colonialidade, é preciso assinalar que a missão ibérica, ao mesmo tempo em que estava consagrada pelo Deus cristão, se ancorava na melhor ciência matemática, cartográfica, náutica em suas grandes navegações. "Navegar é preciso" (Fernando Pessoa), enfim, navegar é coisa do campo da técnica, da precisão, e os portugueses foram grandes navegadores, sobretudo. Não é incompatível a missão salvacionista e evangelizadora com um saber rigoroso, técnico como, mais tarde, na segunda moderno-colonialidade, se tentará fazer crer. A primeira máquina verdadeiramente moderna, o relógio, surgiu nos monastérios da Idade Média exatamente para controlar o tempo das orações de modo objetivo (MUMFORD, 1942 e PORTO-GONÇALVES, 1989). Na verdade, a ciência da segunda moderno-colonialidade está impregnada de um sentido religioso de emancipação. Não nos cansamos de ouvir, ainda hoje, que a ciência opera milagres.

AAmérica experimentará essa razão moderno-colonizadora de um modo muito próprio. Angel Rama, o ensaísta uruguaio, nos chamou a atenção em seu $A$ Cidade das Letras que as primeiras cidades verdadeiramente planejadas racionalmente no mundo moderno-colonial surgiram na América, onde o espaço da plaza foi concebido sob o signo do controle, da dominação. Já, ali, havia desplazados. As primeiras manufaturas moderno-colonizadoras se montaram em Cuba, no Haiti, no Brasil haja visto o açúcar não ser exportado para a Europa in natura, mas, sim, manufaturado. A própria monocultura, enquanto técnica, inicialmente para o cultivo da cana, era uma imposição, haja vista a impossibilidade material de um povo ou uma comunidade qualquer se reproduzir fazendo monocultura para si próprio. Assim, a monocultura não é só a cultura de um só produto, mas também a cultura para um só lado. Por isso a energia da chibata para mover o sistema. Afinal, ninguém faz monocultura espontaneamente até que tenhamos subjetivado as relações sociais e de poder assimétricas e contraditórias (a mão invisível é precedida de outra bem visivel que brandia a chibata). 
Eis as vantagens de falarmos a partir desse outro lugar de enunciação que é a América, particularmente, desde a América Latina e desde uma perspectiva emancipatória nesse momento histórico em que velhos protagonistas, como os indígenas e os afrodescendentes, entram em cena reinventando-se agora com mais visibilidade. AAmérica tem, desde 1492, um papel protagônico na constituição do sistema mundo moderno-colonial (LANDER, 2005 [2000]). É claro que durante um bom tempo não passamos de Índias Ocidentais, nome com que os espanhóis indicavam seu império desde a Ilha de São Domingos até as Filipinas, numa geografia estranha para o que, hoje, fomos e estamos habituados. A América será um nome que se consagrará, como nos ensina Walter Mignolo, com a emergência da descolonização, fenômeno que, para nós, desde a América, se inicia em 1776 (EUA) ainda que revelando a colonialidade do saber e do poder, como nos denuncia o incômodo 1804 (Haiti). Aliás, o Haiti é a melhor revelação de como a liberdade não pode ser pensada ignorando-se a geografia em que está inserida. Toussant de L'Ouverture bem que tentou ser livre nos marcos de uma confederação francesa que, ainda que revolucionária, não via a liberdade se tornar igual para todos e, assim, demonstrava os limites da fraternidade, pois estes princípios não atravessavam o Atlântico e não chegavam à Ilha de São Domingos. Foi preciso outro Jean Jacques, o Dessalines, para proclamar a independência do Haiti e, assim, expressar a vontade geral dos negros haitianos de promover a dupla emancipação tanto da metrópole como dos senhores locais que teimavam em manter a colonialidade. A América ainda hoje abriga essa contradição constitutiva.

Cuba e Porto Rico, que permaneceram sob o domínio espanhol até o final do século XIX, experimentarão o mesmo peso do, então, novo império estadunidense, o mesmo peso que já havia sentido o México quando teve anexado, entre 1845 e 1848, seus amplos territórios do Texas à Califórnia. A fragmentação territorial da América Central expressa essa tensão emancipatória e de dominação, haja visto o caráter geo-estratégico dessa região. Simon Bolívar já o pressentira quando convocara, em 1826, exatamente para o Panamá uma primeira reunião entre Estados que acreditava irmãos e o fazia em contraponto à Doutrina Monroe (1823) que buscava uma integração sob hegemonia estadunidense. A Colômbia sentiu o peso dessas ações imperiais com a amputação do Panamá, em 1903. À época, José Martí percebera essa clivagem consagrando-a com a expressão Nuestra América para se distinguir da outra América, hegemônica. Não olvidemos, pois, que mesmo em nuestra América os novos Estados independentes se fizeram sob a inspiração das Luzes e, assim, o eurocentrismo se faz presente seja pela via da "América para os americanos" (do norte), com a Doutrina Monroe, seja com a Alca ou com os TLCs; enfim, pela colonialidade do saber e do poder. Os povos originários, os afroamericanos e mestiços continuaram submetidos à servidão e à escravização mesmo após a independência. Assim, a colonialidade do saber e do poder sobreviveu ao fim do colonialismo (Quijano). 
Para quem pensa o mundo numa perspectiva emancipatória e a partir da América, sobretudo da América negra, indígena e mestiça e dos segmentos excluídos da riqueza, mas não das relações de dominação e produção, é fundamental compreender esse caráter colonial-moderno do sistema mundo que conformou um complexo de classes sociais embebido na racialidade (Quijano), para que possamos apontar outros horizontes nesse mundo em transformação em que estamos mergulhados. E não é de América Latina, simplesmente, que estamos falando posto que os negros e os índios us-americanos sabem o lugar que ocupam na geografia do poder; como o furacão Katrina recentemente nos revelou em Nova Orleans e na Luisiânia ${ }^{2}$. Afinal, a América é moderna há 500 anos. Aqui se inventou a Revolução (1776) antes dos franceses e iniciou-se a descolonização ainda que permanecendo prisioneiro do pensamento colonial. Outros protagonistas deixaram marcas nessa história, como Tupac Amaru, Tupac Katari, Toussant de L'Orverture e Jean-Jacques Dessaline entre outros. Hoje nos encontramos em plena descolonização do pensamento e, por isso, olhamos o mundo dialogando com o pensamento subalterno que vem sendo construído nesses 500 anos, como nos alertam os zapatistas.

$* * *$

É no período neoliberal do sistema mundo moderno-colonial que a relação entre saberes e territórios vem ganhando um sentido mais intenso. Desde o final da segunda guerra mundial que a centralidade do pensamento europeu vem perdendo terreno junto com a descolonização da África e da Ásia e o surgimento de dezenas de novos estados nacionais num contexto marcado pela guerra fria, mas é a partir dos quentes anos sessenta que o direito à diferença ganha maior visibilidade. Desde então, e como resposta conservadora às "barricadas do desejo", às "greves selvagens" e mesmo à idéia de que o estado é um instrumento de redistribuição de riqueza, que o neoliberalismo começa a combater sistematicamente, sobretudo depois do sangrento golpe de 11 de setembro de 1973, quando inaugura esse novo período em que o papel do estado vai sendo deslocado no sentido do capital. As vitórias de Margareth Thatcher e Ronald Reagan em finais dos anos 70 e inícios dos 80 deram maior consistência ao que mais tarde será chamado neoliberalismo. Não olvidemos, pois, que a primeira experiência de um conjunto de políticas sistemáticas de corte neoliberal se fez em nuestra América, no Chile, em 1976, sob a ditadura sanguinária do General Pinochet. No final dos anos 80 , a queda do muro abriria definitivamente espaço para outras reconfigurações epistêmicas e territoriais.

\footnotetext{
${ }^{2}$ A Venezuela parece estar percebendo que nuestra América tem uma geografia que vai além do rio Grande, quando se dispõe a vender combustível (gasoil) mais barato em alguns bairros pobres de algumas cidades us-americanas, como vimos logo após o furacão Katrina em 2005.
} 
Portugal e Espanha haviam inaugurado, ainda no final da Idade Média, a idéia moderno-colonial de estado territorial soberano que, mais tarde, em 1648, seria consagrada em Westfallia. Diga-se, de passagem, que a presença moura na península ibérica não impediu a convivência de judeus, cristãos e islâmicos. A "limpeza religiosa" dos territórios de Portugal e Espanha nos dá conta da intolerância que esteve subjacente à constituição desses primeiros estados territoriais e, de certa forma, se fará presente enquanto colonialidade do saber e do poder na conformação dos mais diferentes estados territoriais. Lembremos que Santiago, o do caminho de Campostela, é conhecido como mata-mouros. A idéia de uma mesma língua nacional, de um mesmo sistema de pesos e medidas, e de uma mesma religião oficial dá conta do projeto de homogeneização em curso na constituição do estado territorial moderno que, assim, se mostra também colonial em suas fronteiras internas. $\mathrm{O}$ colonialismo não foi simplesmente uma configuração geopolítica por meio do qual o mundo se mundializou. Mas do que isso, o colonialismo constituiu os estados territoriais moderno-coloniais em todo lugar, inclusive, na Europa. A colonialidade é constitutiva das relações sociais e de poder do sistema-mundo nas suas mais diferentes escalas.

Como já demonstramos (PORTO-GONÇALVES, 2001) o território não é algo anterior ou exterior à sociedade. Território é espaço apropriado, espaço feito coisa própria, enfim, o território é instituído por sujeitos e grupos sociais que se afirmam por meio dele. Assim, há, sempre, território e territorialidade, ou seja, processos sociais de territorialização. Num mesmo território há, sempre, múltiplas territorialidades. Todavia, o território tende a naturalizar as relações sociais e de poder, pois se torna abrigo, lugar onde cada qual se sente em casa, mesmo que numa sociedade dividida. Na formulação de Heidegger: "a historicidade de toda humanidade reside em ser enraizado (Heimliche), e ser enraizado (Heimliche) é sentir-se em casa (Heimliche) ao ser desenraizado (Unheimliche)" (Heidegger por CARVALHO, 1999).

O questionamento das fronteiras que hoje se vê é, assim, o melhor indício de que as relações sociais e de poder estão sendo desnaturalizadas. $\mathrm{O}$ questionamento da conformação geográfica de poder conformada no estado territorial nacional vem sendo feito por cima e por baixo no período neoliberal atual do sistema mundo moderno-colonial. Como já indiquei em outro lugar, "abaixo as fronteiras" era um brado tanto dos libertários em 1968, como slogan de gerente de multinacional nos anos setenta (Porto-Gonçalves, 2001). Assim, diferentes territorialidades e os diferentes sujeitos que as portam e agenciam estão reconfigurando os lugares, o espaço. A tensão que hoje vivemos é a melhor expressão que a conformação territorial hegemônica já não consegue mais oferecer abrigo. Gramsci falaria de crise de hegemonia.

Com a própria crise das esquerdas, em parte pela nova configuração do espaço sob hegemonia do capital, onde a fábrica deixa de ser o lócus privilegiado da 
acumulação com a flexibilização locacional e laboral, em parte pela perda da centralidade política dos partidos e dos sindicatos, e ainda em parte pelo estado estar sendo, cada vez mais, capturado pelos interesses do capital, vemos surgir por todo o lado outros protagonistas ${ }^{3}$ nas lutas sociais. Nesse sentido, os Miskitos e a Revolução Sandinista são marcos importantes, sobretudo para a América Latina. O grande levante equatoriano de 1990 e o zapatismo e m 1994 darão visibilidade definitiva a esses velhos protagonistas.

A globalização que muitos acreditavam sócio-culturalmente homogeneizadora se mostrará, ao contrário, estimuladora "da coesão étnica, da luta pelas identidades e das demandas de respeito às particularidades. A universalização, hoje, não é equivalente de uniformidade identitária, mas de pluralidade" (DIAZ-POLANCO, 2004).

A experiência da Revolução Sandinista e o conflito envolvendo os Miskitos são marcos para entendermos o novo padrão de conflitividade que, desde então, passará cada vez mais a ganhar contornos mais claros. Ali, na revolução sandinista (1979), todas as contradições do que significa construir a nação mantendo a colonialidade do saber com a perspectiva eurocêntrica se fará sentir também num regime político de esquerda. A mesma negação do outro já havia sido também experimentada pelos povos originários da Bolívia, na revolução 1952, revolução que não convalidou as formas comunitárias de apropriação da terra e dos recursos naturais, apesar do papel protagônico desempenhado pelos sindicatos e partidos políticos de esquerda. Ao contrário, estimulou a propriedade privada com a distribuição de terras. Acreditava-se à época, à direita e à esquerda, que a diferença era uma condição passageira a ser diluída no todo nacional. $\mathrm{Na}$ revolução sandinista o componente geopolítico do imperialismo operou abertamente estimulando os "contras", assim como qualquer contradição que desgastasse a revolução, como tentou fazer com os miskitos. Todavia, a história dos miskitos se inscrevia em demandas próprias e, talvez, a melhor herança do sandinismo e dos miskitos seja exatamente a legislação que reconhece a autonomia indígena, como afirma Hector Diaz-Polanco, intelectual mexicano que soube compreender o caráter imperialista do apoio dos Estados Unidos, recusando-o.

Não devemos ignorar a importância dos movimentos dos guetos negros das cidades us-americanas desde os Black Panters e Hip Hop até as rebeliões dos anos 80 e inícios dos 90 ("griot"). A trajetória do Hip Hop é, nesse sentido, interessante posto que uma expressão estético-cultural nascida no Caribe se mundializa a partir dos guetos urbanos negros das maiores cidades dos EUA. A

\footnotetext{
${ }^{3}$ Não estamos aqui diante de uma palavra qualquer: protagonista deriva do grego protos, primeiro, principal e agonistes, lutador, competidor (Cunha, 1992:641). Estamos, assim, diante daquele que luta para ser o primeiro, o principal num sentido muito preciso daquele que luta para ser o principio, que é de onde vem príncipe - aquele que principia a ação. Enfim, o cerne da política, a iniciativa da ação. Machiavel soube vê-lo. Daí, O Príncipe.
} 
globalização se complexifica com o estabelecimento de secretas relações que atualizam processos históricos subjacentes ao sistema mundo moderno-colonial, sobretudo a racialidade (Quijano). Em quase todas as cidades latino-americanas o Hip Hop ensejará uma reinvenção da problemática racial com contornos distintos do modo como até então se apresentava, sobretudo entre jovens pobres "quase todos pretos" (Caetano Veloso), mestiços e indígenas. A cultura se politiza.

Desde então, nas mais diferentes reformas constitucionais na América Latina (Nicarágua, Colômbia, Brasil, Equador, Venezuela, Peru, Chile), pela primeira vez se reconhece e se declara o direito à diferença aos negros e aos povos originários, fenômeno que passará a ser conhecido seja como constitucionalismo multicultural (VAN COTT, 2000) seja como pluralismo jurídico ${ }^{4}$ (WALSH, 2002a).

A reconfiguração do estado territorial nacional tradicional, ao mesmo tempo, que reconhece diferentes territorialidades em suas fronteiras internas está imerso naquilo que Jairo Estrada muito apropriadamente chamou constitucionalismo supranacional (Estrada, 2005 e Porto-Gonçalves, 2005), onde ganham curso as determinações emanadas das organizações multilaterais, sobretudo do Banco Mundial, do Fundo Monetário Internacional e da Organização Mundial do Comércio. O Caracazzo, a queda de Alfonsin e a invasão do Panamá pelos EUA, fatos ocorridos no mesmo ano da queda do muro de Berlin, em 1989, nos dão conta das profundas contradições que atravessam a reconfiguração territorial e seus distintos protagonistas. Já em 1990, o levante indígena do Equador dá conta da emergência de novos protagonismos. Em 1994, é o zapatismo que enfrenta a nova configuração territorial neoliberal do mesmo sistema mundo moderno-colonial e apresenta nas ruas e na internet os 500 anos de olvido. Desde então, segundo Atílio Borón, já são 16 os governos democraticamente eleitos derrubados por manifestações de rua na América Latina.

É neste contexto que se apresentam os desafios à emancipação para os variados protagonistas que partem da diferença e põem em debate a questão da diversidade e da igualdade.

\section{Para além do essencialismo (sem abrir mão da diferença)}

Eis que somos remetidos novamente para o debate teórico-político. Como vislumbramos acima, as lutas emancipatórias que advém da diversidade se defrontam

\footnotetext{
${ }^{4} \mathrm{O}$ pluralismo jurídico pressupõe a existência de múltiplas fontes para o direito e não só o Direito Romano. Pelo menos 3 dimensões desses direitos podem ser identificadas: 1- direito ao auto-governo (autonomias); 2- direito especial de representação (Colômbia, p. e.) e 3- direitos poli-étnicos (educação em sua própria língua, etc.).
} 
não só contra aqueles que abertamente se colocam contra o direito à diferença, como os liberais deontológicos e uma certa tradição marxista, quase sempre integracionistas e assimilacionistas, mas também com um certo tipo de multiculturalismo e pluriculturalismo que abre espaço para várias formas de essencialismo: os territorialistas (regionalismo, nacionalismo, bairrismo, localismo), etnicismos e racismos. Não devemos menosprezar, pelas nefastas conseqüências que têm trazido, todos essas modalidades de fundamentalismo. A diferença é tão sutil como radical - todo movimento de afirmação do direito à diferença parte da diversidade cultural como um atributo da espécie humana e, aqui, é preciso ressaltar o caráter cultural dessa diversidade, como invenção de cada povo, para recusar o essencialismo racista. Uma perspectiva emancipatória não pode ver a sua fonte, a diferença, como essência já dada desde sempre e para sempre, mas, sim, como estratégia cognitiva e política de afirmação e construção. Tudo indica que é por um pós-tradicionalismo por onde parece caminhar a revolução indígena em curso. Afinal, mais do que um pós-modernismo celebratório (Boaventura de Sousa Santos), é de um reconhecimento não só da diferença, mas das relações sociais e de poder que as instrumentaliza, o que esses movimentos trazem ao debate. Afinal, o pós-modernismo ignora essa dimensão colonial das relações de poder.

Segundo Catherine Walsh, "a multi ou pluriculturalidade simplesmente parte da pluralidade étnico-cultural da sociedade e do direito à diferença" sendo cada cultura mais uma que se soma ao mesmo sistema de relações sociais e de poder. Enfim, o pluri e o multiculturalismo reconhecem a diferença e a congelam e/ou guetificam. Sabemos como racismo na África do Sul territorializou as diferenças nos bantustões estimulando a diversidade cultural. Estaríamos, aqui, diante daquilo que Diaz-Polanco chamou de liberalismo comunitarista que, dialogando com os novos protagonistas de nosso tempo, vem recusando o individualismo fóbico que tanto caracteriza o velho liberalismos. Talvez o caso colombiano com sua proposta de democracia comunitária seja o que mais venha avançando na direção dessa nova vertente liberal, conforme vem alertando o antropólogo Jaime Caycedo e Diaz-Polanco. Nesse caso temos o contrário do que apontaria uma perspectiva emancipatória, posto que se trata de buscar não só "outras relações entre grupos, como também entre práticas, lógicas e conhecimentos distintos, com o afã de confrontar e transformar as relações

\footnotetext{
${ }^{5}$ Diaz-Polanco (2004) destaca o rico debate que vem sendo travado no interior do campo liberal para o que nos convida a prestar mais atenção, já que não estaríamos diante do mesmo e velho liberalismo. De um lado seria a aceitação da diferença cultural, portanto, de algo que não é mais o indivíduo, mas que seria confinada à ordem liberal. Convicção ou pragmatismo?
} 
de poder (incluindo as estruturas e instituições da sociedade) que naturalizam as assimetrias sociais" (Walsh, 2002a), enfim à interculturalidade e ao que Diaz-Polanco chama de el canon Snorri ${ }^{6}$ (DIAZ-POLANCO, 2004).

Tudo indica que a afirmação da diversidade e o legítimo direito à diferença devam mergulhar na compreensão dos complexos mecanismos por meio dos quais a opressão, a injustiça e a exploração buscam se legitimar, o que significa compreender as relações entre as dimensões cultural, social, econômica e política e buscar novas epistemes entre os protagonistas que estão impulsionando processos instituintes de novas configurações territoriais. Afinal, não é isoladamente que cada grupo subalternizado é mantido nessa condição. É o isolamento de cada qual que é condição do isolamento de cada um. Os limites do localismo se mostram, aqui, evidentes, com a compreensão que não se pode prescindir do lugar e da diversidade. $\mathrm{O}$ divide et impera romano aí está a nos desafiar na busca da afirmação da diferença onde cada qual se reinvente reinventando o conjunto das relações que faz de cada qual ser o que é nesse sistema mundo moderno-colonial marcado pela injustiça, opressão, insegurança e devastação.

\section{O Lugar de possíveis epistemes emancipatórias}

Aníbal Quijano nos mostrou as profundas ligações do que chamou a colonialidade do saber e do poder. A produção de conhecimento que parte da relação sujeitoobjeto, segundo ele, é a mesma que funda a relação do proprietário privado com seu objeto. Assim, mais do que uma episteme há uma relação de poder que diz respeito ao modo como concretamente sobre o terreno se funda a propriedade privada dos bens e as relações de homens e mulheres entre si. O conhecimento seria, nessa episteme, produzido na relação sujeito-objeto e não numa relação intersubjetiva (MIGNOLO, 2003: 231). Já, aqui, se indica uma outra episteme que para ser outra, o outro há que ser outro na sua outridade (LEFF, 2005). Justo o que tem sido negado pela razão que se coloca antes da identidade, parodiando a conhecida tese liberal de Amartya Sen. A natureza, esse outro absoluto (LEFF, 2005), tem sido apropriada por uma razão matemática que, assim, a nega na sua materialidade. No terreno nada abstrato da physis o aquecimento global é a manifestação da combinação da lógica abstrata matemática que nega a natureza e se faz acumulação monetária - lucro. Aqui nessa tensão epistêmico-política novas territorialidades estão sendo engendradas, conforme Arturo Escobar e Líbia Grueso nos mostraram para os afrodescendentes do Pacífico sul da Colômbia e Porto-Gonçalves para os seringueiros da Amazônia brasileira. A natureza é politizada.

\footnotetext{
"El Canon Snorri é "a virtude da tolerância e a aptidão para reconhecer valores alheios" (DIAZPOLANCO, 2004: 231).
} 
Walter Mignolo nos adverte que é a partir das diferenças que novas epistemologias estão emergindo (MIGNOLO, 2003: 235-242). As diferenças só se manifestam na relação, no contato, daí o seu caráter contingente geográfico e social. São epistemologias que emergem no contato de epistemes distintas. Vários autores vêm assinalando esse caráter relacional não essencialista, lugar possível para a emergência de práticas emancipatórias: o pensamento liminar para Walter Mignolo; a exotopia para Mikhail Bakhhtin; o terceiro espaço para-Hommi Bhabha. Catherine Walsh nos fala daqueles que se movem entre lógicas distintas, entre códigos, como é característico dos povos originários da América que há 500 anos convivem com a moderno-colonialidade. Mas essa moderno-colonialidade não se inscreveu num espaço vazio de significação, mas sim em territórios (natureza+cultura) onde foram conformados padrões cognitivos próprios (MIGNOLO, 2003:215). Por isso, mais do que resistência, o que se tem é R-Existência posto que não se reage, simplesmente a ação alheia, mas, sim, que algo pré-existe e é a partir dessa existência que se RExiste. Existo, logo resisto. R-Existo.

Assim como os romanos aprenderam com os gregos, sabemos que os colonizadores se apropriaram do conhecimento nativo para dominá-lo e ocupar seus territórios. Mas depois de 500 anos os zapatistas trazem o México profundo à cena e os bolivianos reinventam Tupac Katari. A elite criolla boliviana sabe, literalmente, o que esse nome lhe traz à cabeça. A totalidade do sistema-mundo é não só contraditória como heterogênea e, assim, não pode ser reduzida à dialética do capital-trabalho. Ou melhor, há heterogênese na totalidade. Embora Marx tenha se colocado de um ponto de vista crítico e emancipatório no interior do capitalismo, não teria percebido a diferença colonial como constitutiva e estruturante do capitalismo, o que é fundamental para compreender a América Latina (Aricó, 1982), como, mais tarde, bem o faria José Carlos Mariátegui. Walter Mignolo nos faz uma interessante provocação quando se pergunta: "se, como condição de sua 'inteligibilidade', a diferença colonial exige a experiência colonial em vez de descrições e explicações sócio-históricas do colonialismo. Suspeito que esse seja o caso e, se for, é também condição para a diversidade epistemológica como projeto epistemológico ..." (MIGNOLO, 2003: 253; os grifos são meus). E aqui temos um bom caminho para a crítica a esse moderno "olhar de sobrevôo" (ARENDT, 1985) que se abstrai do mundo para, de fora, colonizá-lo, o que nos remete à necessidade de um caminhar com, a um conhecimento com.

Gaston Bachelard em seu A Poética do Espaço havia distinguido entre lógica material, aquela que se constrói a partir do atrito, do contato com a matéria, uma lógica do sentimento, e aquela lógica formal que se constrói pelo olhar das formas, lógica matemática, para ele também ocularista. A parafernália de visores, de amplos (tele) visores em cada esquina, em cada lugar, enfim, de sensores à distância (sensoriamento remotos via satélite) nos dá conta da sociedade do controle (Foucault) generalizado que essa lógica comporta (PORTO-GONÇALVES, 2001). Assim, a 
problemática dos saberes não pode descambar para um culturalismo que ignora a materialidade dos fazeres e dos poderes. Afinal, o fazer cotidiano está atravessado o tempo todo pela clivagem da dominação, pelo menos desde 1492 (os maias, os quechuas e os aimaras incluam também os impérios estatalistas dos astecas e dos incas). No fazer há sempre um saber - quem não sabe não faz nada. Há uma tradição que privilegia o discurso - o dizer - e não o fazer. Todo dizer, como representação do mundo, tenta construir/inventar/controlar mundos. Mas há sempre um fazer que pode não saber dizer, mas o não saber dizer não quer dizer que não sabe. Há sempre um saber inscrito no fazer. O saber material é um saber do tato, do contato, dos sabores e dos saberes, um saber com (o saber da dominação é um saber sobre). Há um saber ins-crito e não necessariamente es-crito. Cornelius Castoriadis e o grupo "Socialismo e Barbárie" dedicaram páginas maravilhosas a esses saberes que se fazem desde os lugares, desde o cotidiano, desde as lutas que, de um ponto de vista subalterno, é cotidiana e independente de conflitos abertos da polis.

O poeta brasileiro Caetano Veloso disse que "só é possível filosofar em alemão" e, assim, à sua maneira, associou a episteme ao lugar. Embora o pensamento filosófico tenha um lugar e uma data de nascimento, o pensamento não, como nos ensina Walter Mignolo convidando-nos a não confundir o pensamento filosófico com o pensamento enquanto tal. Assim, uma racionalidade mínima é condição de qualquer comunidade humana e a diversidade de racionalidades o maior patrimônio da espécie, sua expressão maior de criatividade. Talvez a idéia de incompletude de cada cultura, proposta por Boaventura de Sousa Santos, se constitua numa boa perspectiva para fundarmos um novo diálogo de saberes, uma verdadeira política da diferença pósmoderno-colonial, conforme Enrique Leff nos convida, com o auxílio de Emanuel Levinas, abrindo espaço para uma hermenêutica diatópica (Boaventura de Sousa Santos), do que talvez o zapatismo, esse híbrido de pensamento maia com marxismo, e a interculturalidade, esse exotópico/terceiro espaço/gnose liminar, onde também se vê o marxismo dialogando com os quechuas e aimaras, sejam as melhores traduções disponíveis.

DE SABERES E DE TERRITÓRIOS: DIVERSIDADE E EMANCIPAÇÃOAPARTIR DA EXPERIÊNCIALATINO-AMERICANA

Resumo: $\mathrm{O}$ artigo problematiza a relação entre saberes e territórios pondo em questão a idéia eurocêntrica de conhecimento universal. Com isso o autor pretende: (1) retirar o caráter unidirecional que os europeus impuseram a essa idéia (eurocentrismo) e (2) afirmar que as diferentes matrizes de racionalidade constituídas a partir de diferentes lugares são passíveis de serem universalizadas, o que nos obriga a considerar os processos por meio dos quais os conhecimentos podem dialogar, se relacionar. Enfim, o que se visa é um diálogo de saberes que supere a colonialidade do saber e do poder.

Palavras-chave: Saber local - Pensamento Subalterno - Eurocentrismo - Território/ Territorialidades - Diálogo de Saberes 
ABOUT KNOWLEDGES AND TERRITORIES: DIVERSITY AND EMANCIPATION FROM LATINO-AMERICAN EXPERIENCE

Abstract: This article renders problematic the relation between knowledges and territories, by putting in question the eurocentric idea of universal knowledge. In so doing the author intends: (1) remove the unidirectional character Europeans have impose to this idea (eurocentrism), and (2) arguing that different matrixes of rationality constituted through distinct places are liable to be universalized. This can obligate us to consider processes through which knowledges can dialogue, construct relationships. Finally, it aims a dialogue of knowledges to overcome the coloniality of knowledge and power.

Key-words: Local Knowledge - Subaltern Thoght - Eurocentrism - Territory/ Territorialities - Dialogue of Knowledges

\section{BIBLIOGRAFIA}

ALIMONDA, Hector. 2006. Pero jamás podrán quitarme la música... (Notas sobre utopía, identidad, conocimiento en la periferia latinoamericana). Mimeo. ARENDT, Hanna. 1971. Sobre a Revolução. Lisboa: Ed. Moraes.

1987. A Condição Humana. Rio de Janeiro: Forense Universitária.

ARICÓ, José María. 1982. Marx y América Latina. México: Alianza Editorial Mexicana.

BACHELARD, Gaston. 1998. A Poética do Espaço. São Paulo: Martins Fontes.

BAKHTIN, Mikhail. 1999. Marxismo e Filosofia da Linguagem. São Paulo: Hucitec.

BHABHA, Homi. 1994. The Location of Culture. Londres: Routledge.

CARVALHO, José Jorge de. 1999. O Olhar Etnográfico e a Voz Subalterna. Consultado em 20 de agosto de $2006 \mathrm{em}$ http://www.unb.br/ics/dan/ Serie261empdf.pdf.

CAYCEDO, Jaime. 2004. Impacto regional del conflicto colombiano en América Latina. In Ceceña, A. E. (org.) Hegemonias y emancipaciones en el siglo XXI. Buenos Aires: CLACSO.

CASTORIADIS, Cornelius. 1982. A Instituição Imaginária da Sociedade. Rio de Janeiro: Paz e Terra.

CECEÑA, Ana Esther 2006 (Org.) Los desafios de las emancipaciones en un contexto militarizado. Buenos Aires: CLACSO.

CECEÑA, Ana Esther e SADER, Emir. 2002. La Guerra Infinita: Hegemonía y terror mundial (Buenos Aires: Clacso.

DIAZ-POLANCO, Hector. 2004. El Canon Snorri. México: Ed. UACM.

DUSSEL, Enrique. 2005 (2000) Europa, modernidade e eurocentrismo. In: Lander, E. A. Colonialidade do Saber: eurocentrismo e ciências sociais perspectivas latino-americanas. Buenos Aires: Clacso. 
ESTRADA, Jairo. 2006. Las reformas estructurales y la construcción del orden neoliberal en Colómbia. In: Ceceña, Ana Esther (Org.) Los desafios de las emancipaciones en un contexto militarizado. Buenos Aires: CLACSO.

HAESBAERT, Rogério. 2004. O Mito da des-territorialização. Rio de Janeiro: Bertrand Brasil.

HARVEY, David. 1989. A Condição Pós-moderna. São Paulo: Loyola.

LANDER, Edgardo. 2005 (2000) A Colonialidade do saber: eurocentrismo e ciências sociais. São Paulo: CLACSO.

LEFF, Enrique. 2006. Racionalidade Ambiental: a reapropriação social da natureza. Rio de Janeiro: Civilização Brasileira.

MARIÁTEGUI, José Carlos. 1975. As correntes de hoje: o indigenismo - sete ensaios de interpretação da realidade peruana. São Paulo: Alfa Omega.

MIGNOLO, Walter. 2004. Histórias Locais/Projetos Globais. Belo Horizonte: UFMG.

MUMFORD, L. 1942. Técnica y Civilización. Barcelona: Editorial Ayuso.

NIETZSCHE, Friedrich. 2000. Humano, Demasiado Humano. São Paulo: Companhia das Letras.

PORTO-GONÇALVES, Carlos Walter. 1989. Os (Des) caminhos do Meio Ambiente. São Paulo: Contexto.

2001. Geo-grafias: movimientos sociales, nuevas territorialidades y sustentabilidad. México: Siglo Veintiuno.

2003. A Geograficidade do Social. In: Seoane, José (org) Movimientos sociales y conflicto en América Latina. Buenos Aires: CLACSO.

2006a. A Reinvenção dos Territórios: a experiência latino-americana e caribenha. In: Ceceña, A. E. (Org.) Los desafios de las emancipaciones en un contexto militarizado Buenos Aires: CLACSO.

2006b. A Globalização da Natureza e a natureza da globalização. Rio de Janeiro: Civilização Brasileira.

RAMA, Angel. 1985. A Cidade das Letras. São Paulo: Brasiliense.

SEOANE, José (org) 2003. Movimientos sociales y conflicto en América Latina. Buenos Aires: Clacso.

SANTOS, Milton. 1996. A Natureza do Espaço. São Paulo: Hucitec.

SOJA, Edward. 1993. Geografias pós-modernas. Rio de Janeiro: Zahar ed.

SOUSA SANTOS, Boaventura. 2003. Reconhecer para libertar - os caminhos do cosmopolitismo multicultural. Rio de Janeiro: Civilização Brasileira.

2006. A Gramática do Tempo - para uma nova cultura política. São Paulo: Cortez.

VAN COTT, Donna Lee. 2000. The friendly liquidation of the past: The politics of diversity in Latin America. Pittsburgh: University of Pittsburgh Press. WALSH, Catherine. 2002a. Interculturalidad, Reformas Constitucionales y Pluralismo Jurídico Quito: Boletim ICCI- RIMAI, Ano 4, n. 36. 
De Saberes e de Territórios: Diversidade e Emancipação a Partir da Experiência Latino-Americana 2002b Las geopolíticas de conocimientos y colonialidad del poder. Entrevista a Walter Mignolo. In: Walsh, C.; Schiwy, F. e Castro-Gómez, S. 2002. Indisciplinar las ciencias sociales. Geopolíticas del conocimiento y colonialidad del poder. Perspectivas desde lo Andino. Quito: UASB/ Abya Yala.

WOOD, Ellen Maikseins. 2003 (1995) Capitalismo contra democracia. (São Paulo: Boitempo. 
